\title{
Valoración territorial da proposta de traslado dunha oficina de farmacia en Galicia. Un estudo de caso de Xeografía Aplicada
}

\author{
Ángel Miramontes Carballada* \\ Universidade de Santiago de Compostela - Facultade de Xeografía e Historia
}

Recibido: 24 de agosto de 2020 / Aceptado: 19 de novembro de 2020

\begin{abstract}
Resumo
A creación ou traslado dun servizo sempre ten unha serie de repercusións territoriais, pero se ademais se trata dunha farmacia que para exercer a súa actividade ten que cumprir unha serie de condicionantes vinculados ao número de habitantes, á distancia, etcétera, as consecuencias territoriais poden ser variadas. Por iso, a finalidade deste traballo é amosar a repercusión territorial que ocasionaría o traslado voluntario dunha oficina de farmacia dentro do Concello da Estrada (Pontevedra), entendendo como repercusión territorial a súa influencia nas características demográficas, sociais, económicas e de mobilidade da poboación deste espazo do interior de Galicia, así como sobre o servizo básico de distribución de medicamentos á poboación. Para acadar este obxectivo, realizouse un exhaustivo traballo de campo e unha análise de toda a información territorial dispoñible sobre as actuacións que se realizarán, desde o punto de vista de planificación e desenvolvemento territorial, no concello. Unha das conclusións alcanzadas foi comprobar como os límites ou as fronteiras que se crean en ocasións desde a Administración non sempre son as máis eficientes en relación coas características do territorio nin dan o mellor servizo á poboación (áreas educativas, farmacéuticas ou sanitarias).
\end{abstract}

Palabras clave

Xeografía / Saúde / Farmacia / Territorio / Galicia.

\section{Territorial assessment for moving a chemist's in Galicia. A case study of Applied Geography}

\section{Abstract}

The creation or transfer of a service always has a series of territorial repercussions. However, if, in addition, the service is a chemist's that, to do business, must meet a series of conditions (the number of inhabitants and distances among others,) the territorial consequences may be several. The purpose of this work is to show how the voluntary transfer of a chemist's would affect the municipality of A Estrada (Pontevedra). The territorial repercussion would influence the demographic, social, economic and mobility characteristics of the population in this area in the interior of Galicia. The basic service of distributing medicine to the population would also be affected. To achieve this objective, exhaustive fieldwork was carried out along with an analysis of all available territorial information on the actions to be carried out, considering planning and territorial development in the municipality. One of the conclusions reached was to verify how the boundaries or borders that are sometimes created by the administration are not always the most efficient in relation to the characteristics of the territory, nor do they provide the best service to the population (educational, health or pharmaceutical).

\section{Keywords}

Geography / Health / Chemist's/ Territory / Galicia.

JEL Codes: R50.

\footnotetext{
*Correspondencia autor: angel.miramontes@usc.es
} 


\section{Introdución}

Os primeiros traballos de Xeografía da Saúde cunha estrutura similar aos actuais datan das primeiras décadas do século XX. Non obstante, a orixe da Xeografía Médica pódese situar no século XIX da man dos traballos de John Snow, entre os que destaca a análise do comportamento do cólera en Londres por medio de análises urbanas (John Snow Society, 2020). De todos os xeitos, a comezos do século XX centrábanse na difusión espacial das enfermidades a diferentes escalas, principalmente a mundial e a rexional. Co paso das décadas, as temáticas diversificáronse en cuestións relacionadas coas desigualdades, as políticas, o uso e o acceso aos servizos ou as políticas da saúde. A maioría destes estudos realizáronse desde países como Reino Unido, Francia, Alemaña ou EE.UU. (Bailly e Périat, 1995; Crooks, Andrews e Pearce, 2018; Gatrell, 1998, 2002; Haynes, 2016; Howe, 1977; Hunter, 1974; Jones, Gould e Duncan, 2000; Jones e Moon, 1987; Lewis e Mayer, 1988; Pacione, 1986; Pyle, 1980, 1986). Pola súa vez, tamén é importante destacar que a Xeografía da Saúde sempre se atopou integrada por aspectos relacionados con variables demográficas, sociais, económicas e medioambientais, polo que se converte nunha das áreas de estudo da Xeografía onde as metodoloxías son máis multidimensionais, tomando préstamo de economistas, sociólogos ou médicos (Gesler e Kearns, 2002; Gould, 1993; Graham, 2000; Santana, 2005; Serrano, 2016; Whitehead, 1988; Wilkinson, 1996). Así e todo, sobre o obxectivo da Xeografía da Saúde existe bastante consenso, e este céntrase en xerar coñecemento sobre a análise do resultado de políticas sanitarias e mais da organización dos servizos na saúde das poboacións e no desenvolvemento do territorio (Santana, 1995, 2005).

De aí que a figura do xeógrafo se entenda como fundamental dentro dos frecuentes cambios de localización ou privatización de servizos da saúde a escala mundial, debido a que o territorio é unha causa e un efecto dos problemas da saúde. As nocións de distancia, estrutura socioeconómica, accesibilidade ou servizos de saúde son básicos dentro da actual Xeografía, e pensamos que tamén da Economía. De todos as maneiras, tamén se percibe que é necesario realizar máis estudos a escala rexional, e sobre todo local, avaliando, entre outros, o acceso á saúde da poboación, dos grupos máis vulnerables, a localización óptima para implantación de novos servizos sanitarios. Así, por exemplo, os traballos sobre o equilibrio entre a utilización de servizos e a saúde (Davies, 1968; Harvey, 1973; Knox, 1975; Morrill e Earicson, 1970; Price e Blair, 1989; Santana, 1995; Townsend e Davison, 1988), os modelos de optimización da localización dos servizos (McAllister, 1976; Morril, 1974; Scott, 1970; Teitz, 1968 ) ou as políticas de privatización e de reordenación espacial da oferta de servizos de saúde (Mohan, 1988; Navarro, 1976). A diversidade de métodos tamén é ampla, e algúns están moi vencellados co empregado no presente traballo, como é a avaliación das distancias percorridas polos usuarios (Mayhew, 2018; Paul, 1985) ou os estudos sobre o consumidor, a accesibilidade e o fluxo de enfermos (Mayhew e Leonardi, 1984). Nesta liña de traballo, Santana (1995) incide en que a accesibilidade resulta da relación entre a localización dos bens e a localización dos clientes, tendo en conta os recursos, a existencia e as características de transporte privado e/ou público, tempo, distancia e custo. Outra tipoloxía de variables que cómpre ter presentes, e que tamén estudamos neste traballo, son as relacionadas coas características demográficas (Agbonifo, 1983).

Ao estudar a accesibilidade dun ben ou servizo de saúde, como é unha oficina de farmacia, débese ter en conta a oferta e a demanda, entendendo como oferta a localización e as características sociais dos servizos e, relacionados coa demanda, as características dos clientes. En ambos os casos xorden factores que cómpre ter moi presentes, como o capital social, o cultural ou o tipo de servizos públicos e/ou privados. Xa que logo, sempre se deberán considerar as tres dimensións relacionadas coa accesibilidade: as características do territorio (tempo e custo entre fogar e servizo), os clientes potenciais (xénero, idade, seguro médico, etcétera) e a oferta de servizos. A accesibilidade está directamente relacionada coa orixe, co destino e mais coa ponderación da distancia en tempo e custo (Banister, 2011; Comber, Brunsdon e Radburn, 2011; Santana, 1995; Vasconcellos, 2000; Zaidi, 1994). De todos os xeitos, a accesibilidade non só depende da localización, senón da capacidade de superar certas barreiras ou malos accesos (Ferraz e Torres, 2004; Kravitz et al., 2011; Santana, 2005), polo que é moi importan- 
te coñecer a área de influencia real dun determinado servizo sociosanitario (Garb e Wait, 2011; Josep e Phillips, 1984; Knox, 1978). De feito, existen afirmacións de mediados da década dos 80 do século XX que argumentan que as persoas que teñen que facer desprazamentos superiores a $4 \mathrm{~km}$ ata os servizos de saúde teñen unha situación de desvantaxe. Porén, non existe unha relación uniforme entre o aumento da distancia e a diminución do emprego de servizos da saúde como unha farmacia. Así, en ocasións o efecto negativo da distancia pódese contrarrestar co tamaño, a calidade da atención, a imaxe, os horarios, entre outros factores (Kleindorfer, Xu, Moomaw, Khatri, Adeoye e Hornung, 2009; McLaren, Ardington e Leibbrandt, 2013; Moïsi et al., 2011).

Unha realidade que garda relación co obxectivo deste traballo é a confirmación de que os servizos sociosanitarios atraen a poboación da súa área directa de influencia, pero tamén doutras áreas, en función das súas condicións específicas, e sen importar outro tipo de límites ou fronteiras como pode ser o cambio dun municipio a outro.

Por outro lado, tamén é moi importante ter en conta que a distribución dos locais ou servizos no territorio, ademais de gobernarse por criterios mercantilistas e capitalistas, seguen unha lóxica de localización en función do punto de vista da Xeografía. Dentro desta ciencia, existen os denominados modelos espaciais, que combinan a economía e o territorio, entre os que destacan os modelos tradicionais de von Thünen (1876), Weber (1909), Christaller (1933), Lösch (1940), Isard (1956) ou Krugman (1992) (Fujita e Krugman, 2004). 0 entendemento da dinámica espacial en economía serve non só para satisfacer as necesidades dos clientes, senón tamén como instrumento para un ordenamento territorial nas cidades ou vilas onde se produzan este tipo de focos de acumulación e circulación de bens e servizos; e máis aínda cando en Galicia, desde mediados do século XX, existe o consenso de que deixou de ser unha sociedade rural para converterse nun territorio que debe de ser interpretado a partir dos seus espazos urbanos, tanto as cidades como os núcleos que actúan como cabeceira de ámbito comarcal. En consecuencia, dentro da estrutura territorial de Galicia diferenciamos un conxunto de espazos centrais, definidos por unha concentración de actividades económicas e demográficas, e outro, de espazos periféricos nos que predomina o proceso de abandono, envellecemento e escaso dinamismo económico (Lois, 1993, 2005; Precedo, 1974, 1987; Rodríguez, 1997, 1999). Neste sentido, os estudos máis significativos dentro da Xeografía da Saúde a escala galega centralízanse na figura do catedrático Jesús Manuel González Pérez, que comezou a súa especialización neste tema coa tese doutoral Introducción al estudio de la geografía de la salud en Galicia: las provincias de Pontevedra y Ourense, e con obras posteriores nas que se discute a ordenación territorial da saúde (entre outras, González Pérez, 2001).

Desta forma, seguindo a liña dalgúns dos traballos comentados sobre a Xeografía da Saúde, lugares centrais ou migración de servizos, o obxectivo principal deste traballo é realizar a valoración territorial que supoñería o traslado dun servizo sociosanitario, como é unha oficina de farmacia, dentro dun mesmo municipio. Neste obxectivo influirán tanto as características do territorio como a existencia dunha normativa que limita o traslado ou a apertura deste tipo de establecementos cunha serie de criterios ríxidos e estándares que non teñen en conta os dinamismos e as alteracións que sofre o territorio. Polo tanto, a investigación ten dous obxectivos secundarios fundamentais para acadar o principal: o primeiro, unha aproximación ao estudo das variables máis territoriais da normativa farmacéutica e a distribución das oficinas de farmacia en España; e o segundo, a análise das características territoriais dun municipio do interior de Galicia (poboación, dotación de servizos, infraestruturas, etcétera). Ademais, o obxectivo principal ten como característica engadida que coincide co dunha investigación "real", un estudo de caso; un claro exemplo dun traballo de Xeografía Aplicada centrado na área da Xeografía da Saúde.

\section{Materiais e métodos}

A investigación deriva dun contrato entre os titulares dunha farmacia e un grupo de xeógrafos para a execución dun informe no que se realizase unha valoración territorial das potencialidades e debili- 
dades que supoñería o traslado dunha oficina de farmacia dentro do mesmo concello. Este informe, ademais de para o seu propio coñecemento, empregaríase para a realización dun peritaxe xudicial e a posterior defensa por parte dos seus autores perante un tribunal. Finalmente, o documento foi presentado como informe pericial e defendido ante o Tribunal Superior de Xustiza de Galicia fronte á oposición doutras oficinas de farmacia e ante a posibilidade de que se producise o traslado da dita oficina. Estímase que, na segunda metade do ano 2020, se saberá o que resolva o alto tribunal coa proposta de traslado.

A realización dese informe pódese considerar como o embrión do artigo científico. Ao longo do proceso ata a redacción final do presente traballo, desbotamos apartados do informe e, por outro lado, preocupámonos por ampliar outros. De feito, o artigo presenta un completo estudo sobre o estado da cuestión da Xeografía da Saúde e, especialmente, do relativo á localización dos seus servizos, como pon de manifesto a ampla referencia ao seu estudo no contexto internacional. A partir da análise dunha serie de factores como demanda, oferta, accesibilidade, por citar só algúns, relaciónase a súa presenza con toda unha serie de repercusións territoriais e sociodemográficas, o que evidencia, ao noso entender, o interese xeográfico e económico deste traballo.

En canto ao método empregado para a execución do artigo, realizouse un exhaustivo traballo de campo. En varias ocasións desprazámonos á parroquia de Oca, no municipio da Estrada (Pontevedra), para coñecer in situ a localización da farmacia e comprobar a súa accesibilidade, conexión coas vías de comunicación, proximidade e acceso ao centro de saúde, comunicación coas entidades de poboación, zonas de aparcamento, etcétera. Nesta análise tamén comprobamos os tempos reais camiñando e en coche ás outras oficinas de farmacia próximas, así como un estudo da parroquia de San Paio, núcleo urbano e cabeceira comarcal da Estrada, no que están a executar un gran centro de saúde e para onde solicitan o traslado da oficina de farmacia. A análise sobre as características principais da localización actual e a proposta planeada completámolo empregando técnicas cartográficas e de fotointerpretación para chegar ás nosas reflexións finais con softwares libres e básicos como Google Maps ou GeoMap (Barredo, 1997; Bosque e Franco, 1995; Bosque e Moreno, 2004; Carver, 1991; Janssen e Rietveld, 1990; Pereira e Duckstein, 1993; Voogd, 1983).

Ademais, manexamos as bases de datos oficiais de economía e, principalmente, de poboación do Instituto Nacional de Estadística (INE) e do Instituto Galego de Estatística (IGE). Os datos estatísticos oficiais permitíronnos ir completando os resultados do traballo executado neste municipio do interior da provincia de Pontevedra, así como a consulta de toda a normativa e lexislación existente relacionada coa instalación ou co traslado dunha oficina de farmacia en Galicia.

A estrutura do artigo é clara. En primeiro lugar, realízase un estado da cuestión onde se sintetiza a escala internacional a Xeografía da Saúde. En segundo lugar, desenvólvense os contidos do obxectivo secundario, que se correspondía co estudo da normativa farmacéutica en España. En terceiro lugar, efectuouse a caracterización territorial do estudo de caso (localización, poboación, infraestruturas, entre outras), que se corresponde con outro obxectivo secundario, e en cuarto e último lugar, utilizando os resultados de cada un dos obxectivos secundarios, redactáronse as conclusións e déuselle resposta ao obxectivo principal deste artigo, realizando un razoamento final sobre a idoneidade ou non do dito traslado.

\section{Breve exposición da normativa farmacéutica e distribución das oficinas de farmacia en España}

En España, a apertura dunha nova farmacia atópase ligada á obtención da correspondente autorización de instalación, que concede o departamento de sanidade competente en cada comunidade autónoma. Desde cada rexión convócanse, con certa frecuencia, concursos de aperturas de oficinas de farmacia, segundo o disposto no artigo 3 da Lei 16/1997, de 25 de abril, de regulación de servizos das oficinas de farmacia. Máis alá destes concursos, o único xeito de poñer en marcha unha farmacia é com- 
prando unha licenza xa existente, ou por medio da herdanza. Na actualidade, o prezo medio destas licenzas en España, salvo excepcións, non baixa dos 600.000 euros, segundo os datos de diferentes empresas que se dedican a asesorar aos interesados na compra e venda de licenzas de farmacia, como FarmaQuatrium (2019) ou Farmaconsulting (2019).

Ademais, a normativa tamén establece unha serie de requisitos en canto á localización da farmacia, tanto de nova creación como de traslado, sendo este último acontecemento o que nos concirne dentro do presente traballo. E é que, ao estar tan reguladas e considerarse un servizo público, non se pode abrir unha farmacia en calquera lugar, senón que deben repartirse ao longo de todo o territorio a fin de que a poboación estea ben abastecida e cuberta por este servizo dun modo homoxéneo. De feito, en España hai 22.028 oficinas de farmacia, o que representa 2.121 habitantes por farmacia. Non obstante, en Galicia hai 1.344 farmacias e un número menor de potenciais clientes por farmacia: 2.010 persoas. De todos os xeitos, detéctase que o tramo do número de persoas por farmacia a escala rexional se sitúa entre as 2.643 persoas do País Vasco e as 1.077 de Navarra (máis alá dos casos de Melilla ou dos arquipélagos, cuns valores que superan as 3.500 persoas). Isto indícanos que existe unha considerable heteroxeneidade entre a rendibilidade económica que pode ter un establecemento e o servizo que lle da á poboación segundo a comunidade autónoma na que nos atopemos (Consejo General de Colegios Oficiales de Farmacéuticos, 2019).

En efecto, a homoxeneidade territorial entre a poboación e o número de oficinas de farmacia, que pretende conseguir a normativa, non é equitativa para toda España (ver Figura 1). 0 motivo deste desequilibrio, sen ser nesta ocasión o obxectivo do presente estudo, atópase detrás da distinta tipoloxía de asentamentos de poboación e os valores de densidade demográfica. Así, as comunidades que presentan un maior desequilibrio son, por un lado, as dúas Castelas e, polo outro, Madrid e Cataluña.

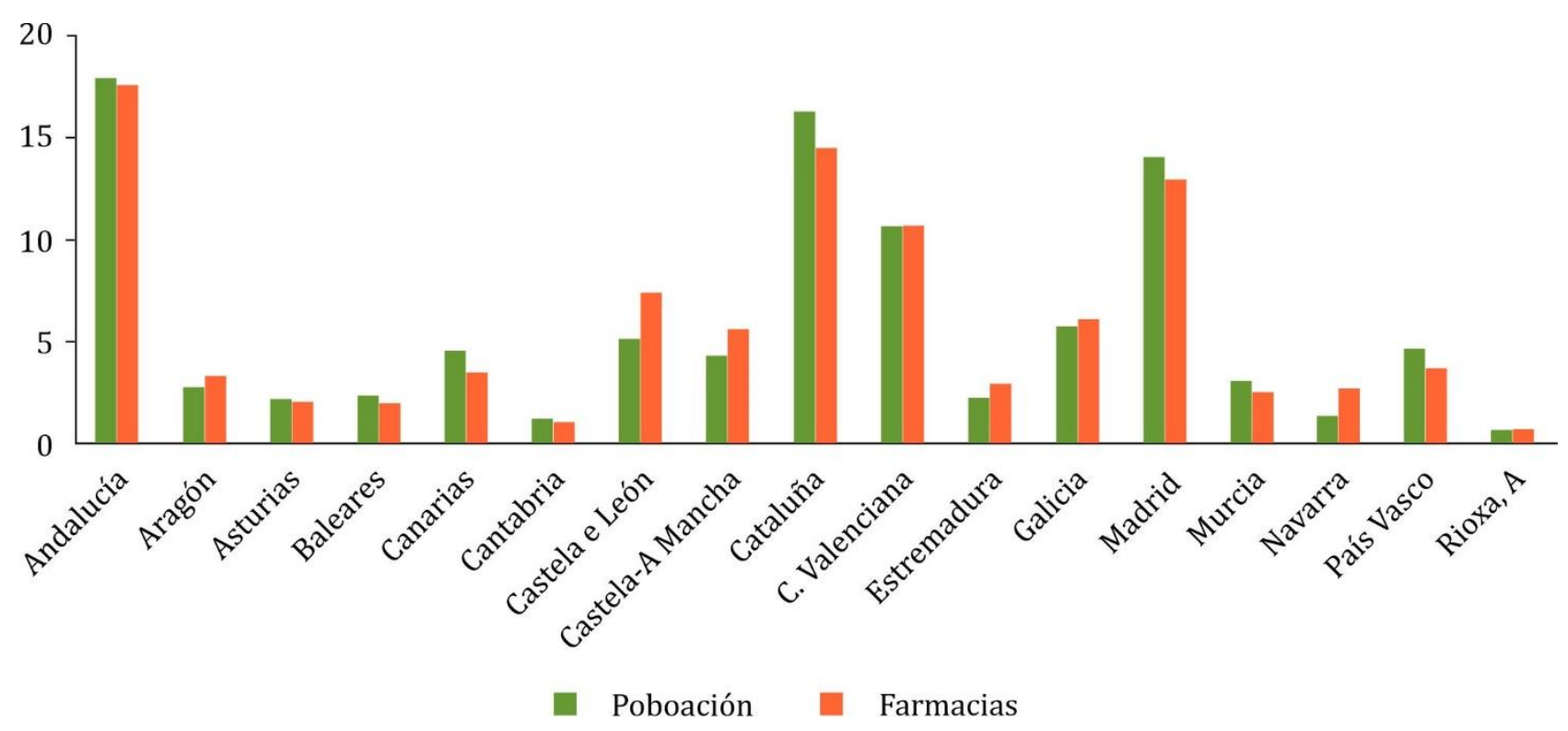

Figura 1. Porcentaxe de número de habitantes e farmacias de cada unha das comunidades autónomas sobre o total de España. Fonte: elaboración propia a partir dos datos facilitados polo Consejo General de Colegios Oficiales de Farmacéuticos (2019).

En canto aos requisitos territoriais que se deben cumprir para abrir unha farmacia, destacan:

1) En cada zona farmacéutica só se poderá crear unha farmacia por módulo de 2.800 habitantes.

2) Tan só se poderá abrir unha farmacia adicional se se supera a dita proporción, a cal se creará por unha fracción superior a 2.000 habitantes. 
3) Cada farmacia deberá respectar unha distancia mínima respecto ás farmacias existentes, que, por regra xeral, será de 250 metros.

Unha vez concedida a autorización de instalación, débense formalizar unha serie de requisitos adicionais. Estes son algúns dos máis importantes: ter o título académico universitario de licenciado ou graduado en Farmacia; número de colexiado ou colexiada do titular dentro dalgún dos colexios oficiais de farmacéuticos (en España hai 52); escritura de compravenda do local ou contrato de arrendamento ou documento que demostre a súa dispoñibilidade, sempre dentro das zonas delimitadas na convocatoria (valórase adoito a situación e as distancias con respecto ás outras oficinas de farmacia situadas nos arredores, así como aos centros de saúde existentes ou cuxa construción estea prevista); plano do local acompañado da memoria explicativa da distribución das diferentes dependencias de que consta a farmacia; plano de situación; declaración de ter os produtos químicos, así como os aparellos e utensilios, tal e como ordena a Farmacopea Española IX edición, e mais os medicamentos de urxencia que esixe a Orde de 5 de maio de 1965.

Esta documentación é xeral para toda España, e tamén se solicitarán outros informes, non tan específicos para a apertura dunha farmacia, como os de seguridade ou incendios, entre outros, ademais dalgunha documentación engadida que pode variar dunha comunidade autónoma a outra. Por exemplo, en Galicia atopámonos coa recente aprobación dunha reforma da Lei de ordenación farmacéutica de Galicia de 1999 mediante a actual Lei 3/2019, de 2 de xullo, de ordenación farmacéutica de Galicia. Logo de 20 anos de inmobilismo legal, non se introduciron grandes cambios, pero si un certo interese en que o servizo chegue a toda a poboación, permitindo, por exemplo, que as farmacias poidan abrir sucursais en poboacións que carezan de servizo. De feito, na sección 4 desta Lei recóllese a planificación e a ordenación territorial de novas oficinas de farmacia. Non é preciso realizar unha análise exhaustiva para detectar algunha debilidade como a ausencia de criterios territoriais ou de planificación territorial aplicada. Por exemplo, no artigo 31, "Zonas farmacéuticas", indícase que se toma como base para a planificación as unidades de atención primaria, que en moitas ocasións se corresponden coas demarcacións dos municipios. Porén, para ordenar as zonas farmacéuticas non as teñen en conta, e crean a maiores tres zonas farmacéuticas:

1) Zonas farmacéuticas urbanas: correspóndense cos municipios de máis de 30.000 habitantes.

2) Zonas farmacéuticas semiurbanas: correspóndense cos municipios dun número de habitantes comprendido entre 10.000 e 30.000 .

3) Zonas farmacéuticas rurais: correspóndense cos municipios de menos de 10.000 habitantes.

Inmediatamente, tras a lectura desta zonificación, xorden infinidade de preguntas e debilidades territoriais: todos os municipios de Galicia de máis de 30.000 habitantes teñen as mesmas características territoriais?; é o mesmo Vilagarcía de Arousa, con 37.519 habitantes, que Lugo, con 98.025?; inflúe a chegada de turistas?; e a presenza de grandes empresas ou sedes da Administración en municipios onde os traballadores non teñen por que estar empadroados?; etcétera. A todas estas preguntas a recente Lei responde asegurando que o Consello da Xunta de Galicia poderá acordar a declaración de determinadas zonas farmacéuticas como especiais.

Ademais, confírmase que, dentro da planificación e da ordenación das oficinas de farmacia, as variables de poboación e de distancias son as que predominan e marcan (con total potestade) a distribución territorial deste servizo sociosanitario. De feito, o artigo 32 establece uns módulos para o cálculo das oficinas de farmacia que corresponden a cada zona. Estes módulos tamén nos provocan unha serie de dúbidas que comentamos, a seguir, na análise das distintas zonas:

1) Zonas farmacéuticas urbanas: unha farmacia por cada 2.800 habitantes empadroados. Séguese o criterio que se estipula a escala en toda España, salvo que se supere esa proporción en 1.500 habitantes, suposto no que se poderá establecer unha nova oficina de farmacia sempre e cando se cons- 
tate un incremento neto da poboación desa zona nos últimos cinco anos. Novamente, o criterio temporal transmítenos incerteza ante a efectividade deste delimitador.

2) Zonas farmacéuticas semiurbanas: unha por cada 2.500 habitantes empadroados, agás que se supere esa proporción en 1.500 habitantes, suposto no cal se poderá establecer unha nova oficina de farmacia sempre e cando se constate un incremento neto da poboación desa zona nos últimos cinco anos. Novamente, é significativo, baixo o noso punto de vista, o emprego de valores absolutos, como 1.500 habitantes, co que non se aplicaría se aumenta en 1.499, ocasionando un desequilibrio entre a rendibilidade e a carga de traballo das oficinas de farmacia. Polo tanto, sería máis correcto o manexo de tendencias ou porcentaxes.

3) Zonas farmacéuticas rurais: unha farmacia por cada 2.000 habitantes empadroados, salvo que se supere esa proporción en 1.500 habitantes, suposto no que poderá establecerse unha nova oficina de farmacia sempre e cando se constate un incremento neto da poboación desa zona nos últimos cinco anos.

Por outro lado, o artigo tamén confirma que en cada concello poderá haber, cando menos, unha oficina de farmacia. Trátase dunha medida positiva e coherente para poderlle ofertar este servizo sociosanitario a toda a poboación. Porén, comprobamos como "contradí" o criterio delimitador do número de habitantes, pois en Galicia un 43\% dos municipios teñen menos de 2.000 habitantes (IGE, 2019).

Finalmente, o artigo 32 estipula que para o cómputo de habitantes se teña en conta a poboación que conste na última revisión do padrón municipal vixente no momento de se iniciaren os traballos necesarios de cara á aprobación do mapa farmacéutico.

A outra variable máis determinante dentro da ordenación territorial das farmacias é a variable das distancias. 0 artigo 33, "Distancias entre as oficinas de farmacia", incide en catro aspectos:

1) 0 establecemento dunha oficina de farmacia por razón de nova instalación ou por cambio de localización non poderá facerse a unha distancia inferior a 250 metros doutras oficinas de farmacia ou dun centro público de asistencia sanitaria en funcionamento ou cuxo emprazamento estea previsto pola consellería competente en materia de sanidade. É a mesma distancia que xa se reflectía a escala para toda España. Este punto si que entra en liza no tocante á valoración territorial da proposta de traslado da oficina de farmacia que nos concirne, pois a nova farmacia estará moi próxima ao centro de saúde que se está construíndo na Estrada. Con todo, a disposición non terá efecto, xa que a solicitude foi realizada antes da licitación oficial de construción do novo servizo sanitario.

2) Excepcionalmente, naquelas zonas farmacéuticas que conten cunha única oficina de farmacia, poderá non esixirse esa distancia mínima cando concorran razóns de interese xeral que así o xustifiquen.

3) Regulamentariamente se fixará o procedemento, as condicións e os criterios para efectuar a medición das ditas distancias.

4) Nos cambios de localización forzosos provisionais con obrigación de retorno, as distancias mínimas ás que se refire o número 1 deste artigo reduciranse a 125 metros.

En definitiva, percibimos unha certa lasitude na fixación dos criterios de distancias, o que deixa "a porta aberta" á presentación de moitas razóns de interese xeral ou excepcións que debilitan a rixidez dos 250 metros mínimos.

0 artigo 34 céntrase no mapa farmacéutico, e indica que os criterios de planificación farmacéutica incluídos na presente Lei se concretarán neste mapa, que se tramitará de acordo co procedemento regulamentariamente establecido e será aprobado polo Consello da Xunta de Galicia. O primeiro punto do artigo prodúcenos satisfacción, ao comprobar como se lle conceden moitas competencias á execución dun mapa. De todos os xeitos, detectamos unha primeira debilidade, pois o mapa farmacéutico relacionará todas as zonas farmacéuticas da Comunidade Autónoma de Galicia segundo sexan urbanas, semiurbanas ou rurais. Ademais, o mapa conterá un anexo coas novas oficinas de farmacia e as súas 
delimitacións territoriais concretas, indicando aquelas que teñan vinculada unha caixa de urxencias para cubrir as necesidades daqueles lugares en que, por carecer de entidade suficiente para a apertura dunha oficina de farmacia ou por tratarse de zonas especiais de difícil accesibilidade, non se poida instalar unha nova oficina. Este é outro dos puntos que se propón dentro da solicitude de traslado da oficina de farmacia, deixando aberta a posibilidade de instalar unha caixa de urxencias na localización actual para lle dar servizo á poboación da parroquia de Oca.

o lexislador "protéxese" ao afirmar que o mapa farmacéutico poderá ser revisado cando se detectasen alteracións significativas no padrón ou outras circunstancias que impliquen cambios nas necesidades de atención farmacéutica dunha ou varias zonas. Igualmente, establece que a Administración local ou os colexios oficiais de farmacéuticos poderán instar ante a consellería competente en materia de sanidade a revisión do mapa farmacéutico.

En resumo, e aínda que somos conscientes da dificultade que existe para a planificación territorial dun servizo sociosanitario como pode ser unha farmacia, percibimos unha serie de debilidades claras e manifestas que amosan o descoñecemento das características do territorio por parte do lexislador, ou ben que non tiveron en conta ou non procuraron o asesoramento de analistas territoriais.

\section{Resultados. Caracterización territorial da área de estudo: peculiaridades, poboación e localización}

Para a valoración territorial do traslado da oficina de farmacia dunha parroquia a outra dentro do municipio da Estrada (Pontevedra), ademais de ter en conta toda a lexislación e normativa vixentes, realizouse unha análise territorial municipal. Esta análise dividiuse en tres grandes apartados. En primeiro lugar, unha caracterización territorial do municipio; en segundo lugar, un estudo demográfico; e, en terceiro lugar, unha análise da localización territorial actual e da localización proposta da oficina de farmacia. Os resultados de cada unha destas partes expóñense a continuación, e son a base das conclusións.

\subsection{Peculiaridades básicas do municipio da Estrada (Pontevedra)}

Desde hai varias décadas, e como indicaron múltiples autores, considérase pertinente amosar as características básicas dun territorio, pois unha mesma actuación e coas mesmas peculiaridades, como pode ser a creación dunha infraestrutura ou a dotación dun novo servizo, sobre territorios diferentes pode ter consecuencias moi dispares. Non é o mesmo actuar nunha área urbana que nunha rural ou nunha periférica (Cooke, 1985; Gilbert, 1988; Massey, 1984, 1990; Miramontes Carballada (2016); Smith, 1984; Urry, 1981).

En primeiro lugar, é necesario recordar que A Estrada é un municipio de máis de 20.000 habitantes, unha cabeceira comarcal que exerce claramente o seu poder de atracción sobre a poboación de todas as parroquias da área rural e doutros municipios adxacentes como Cuntis, Silleda ou Forcarei. Estes municipios limítrofes son dun rango demográfico menor e cunha dotación de servizos e ofertas comerciais que teñen que complementar coa ofertada desde o núcleo urbano da Estrada. A modo de exemplo, é frecuente que alumnado do IES García Barros da Estrada sexa de municipios veciños como Cuntis ou Silleda. Igualmente, as carteiras de clientes das tendas de electrodomésticos ou moda inclúen moitas persoas de fóra da Estrada. Por esta razón, atopámonos cunha área de influencia de servizos públicos e privados que vai máis alá dos límites administrativos municipais, algo que, como se verá, tamén sucede coas áreas de influencia das farmacias, que abarcan máis que os límites administrativos dun determinado municipio.

O Concello da Estrada sitúase no norte da provincia de Pontevedra, e limita ao norte co río Ulla, que o separa dos municipios coruñeses de Padrón, Teo, Vedra e Boqueixón; ao sur, con Campo Lameiro e 
Cerdedo-Cotobade; ao leste, con Forcarei e Silleda; e ao oeste, con Cuntis, Pontecesures e Valga (ver Figura 2).

A súa extensión, 294,64 km² aproximadamente, convérteo nun dos máis extensos de Galicia. Ten 51 parroquias e 458 entidades de poboación, sendo a vila da Estrada a entidade máis importante, que se corresponde coa parroquia de San Paio.

O núcleo urbano aséntase a 287 metros de altitude e é o centro organizador desta dispersión relativa que presenta o municipio. A Estrada posúe un sistema de asentamentos de poboación que dificulta a xestión, dotación e distribución dos servizos públicos e privados ao longo de todo o municipio. A parroquia de San Paio é a cabeceira do partido xudicial que inclúe os municipios da Estrada e Forcarei.

Segundo os datos actuais e oficiais do IGE (IGE, 2018), no ano 2017 A Estrada tiña 20.700 habitantes, dos que o $52 \%$ son mulleres. Ao analizar a poboación do municipio por idades, apréciase un envellecemento bastante pronunciado, onde a poboación menor de 15 anos representa o $12 \%$, a de 16 a 64 anos, o $61 \%$ e os maiores de 65 anos, o $27 \%$. De todos os xeitos, conta cunha porcentaxe de poboación en idade de traballar suficiente, o que lle concede un futuro mellor que o doutros municipios galegos. Ademais, como veremos no apartado do estudo demográfico, algunhas parroquias como a do núcleo urbano da Estrada ten valores máis positivos. Nesta mesma parroquia, San Paio, é onde se localiza a maioría das 365 persoas estranxeiras do municipio, coas consecuencias positivas que iso supón como diversidade cultural, social e incremento dos valores demográficos (absolutos e, polo xeral, de natalidade).

O movemento natural da poboación (diferenza entre nacementos e defuncións) no municipio foi negativo, de -112 persoas. Porén, o saldo migratorio é positivo en máis de 64 persoas que inmigraron fronte ás que emigraron. Trátase este dun valor para ter moi presente á hora de valorar o dinamismo demográfico e socioeconómico que pode chegar a ter un municipio das características territoriais da Estrada. Ademais, a porcentaxe maior da procedencia dos inmigrantes, o 28\%, é doutra provincia. Este factor é posible porque A Estrada limita ao norte coa provincia da Coruña, cos municipios de Padrón, Boqueixón, Teo e Vedra. Esta proximidade entre municipios é a que permite os movementos pendulares (todos os días de ida e volta ao domicilio) de poboación dos municipios adxacentes ao núcleo urbano da Estrada.

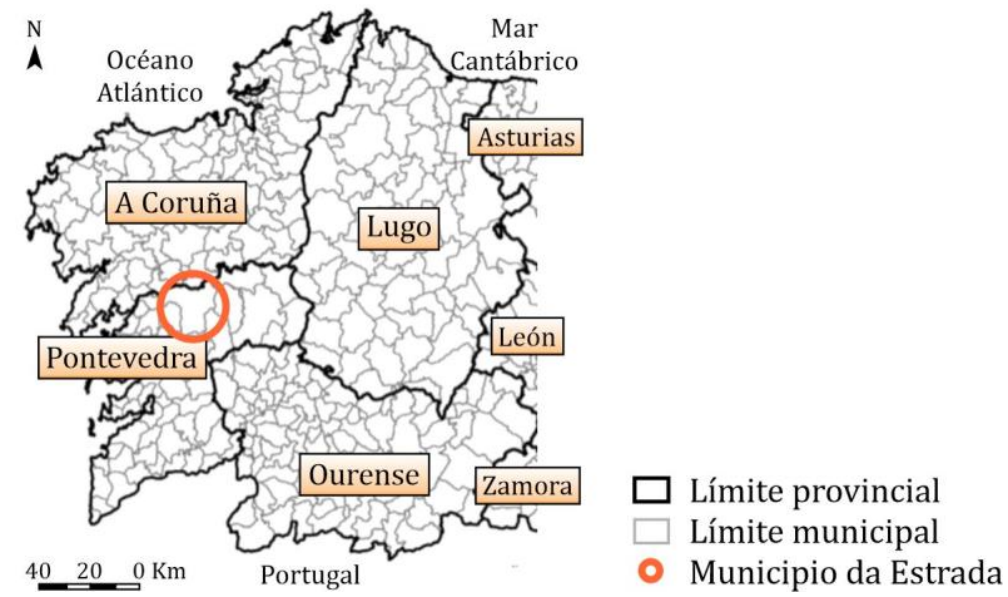

Figura 2. Localización do municipio da Estrada no mapa provincial e municipal de Galicia. Fonte: elaboración propia.

Polo que respecta a infraestruturas e vías de comunicación, o municipio da Estrada e a súa parroquia urbana son atravesados pola nacional N-640 que vén do interior da provincia de Ponteve- 
dra (Lalín, Silleda...) e continúa cara á cidade de Pontevedra e ás Rías Baixas galegas. A área oeste do municipio é atravesada por outra estrada nacional, a N-525, que vén de Ourense e vai cara a Santiago de Compostela. Cun trazado similar está unha estrada de pago, a AP-53. Así mesmo, conta cos diferentes enlaces que existen coa AP-9 (a verdadeira columna vertebral de comunicación do territorio galego). En consecuencia, a poboación da Estrada está moi ben comunicada por estrada, pois está a 20 minutos de Santiago de Compostela, a 40 de Pontevedra e a 60 minutos da Coruña, Lugo, Ourense e Vigo. Por outro lado, dispón dun aeroporto a 30 minutos e dunha estación de tren a 20 (en Santiago de Compostela). Así e todo, aínda resulta máis significativo saber que estes tempos de desprazamento en automóbil serán menores no momento en que se termine a autovía que une A Estrada coa cidade de Santiago de Compostela (na actualidade está construído xa a metade do traxecto).

En relación coa estrutura económica do municipio da Estrada, detéctase un claro proceso de terciarización, onde as empresas do sector servizos representan o 56\% do tecido empresarial e o $68 \%$ dos afiliados laborais de todo o municipio. Ademais, estas porcentaxes do proceso de terciarización aumentarán, con total seguridade, nos próximos anos. De feito, na vila da Estrada están sucedendo unha serie de actuacións centradas na dinamización da actividade comercial. Estes acontecementos pódense dividir en tres. 0 primeiro foi a creación da infraestrutura do Novo Mercado, que aglutina nun mesmo espazo -a praza de abastos do concello- un viveiro de empresas de nova creación, un centro de día e un espazo de usos múltiples. A segunda actuación é a instalación dun área comercial na parte leste do trazado urbano da Estrada (a pouca distancia do novo centro de saúde) liderada pola empresa Lidl. A terceira actuación, moi similar á segunda, aínda que cunha maior envergadura, é o asentamento na área oeste do núcleo urbano dunha área comercial centralizada arredor da empresa Mercadona. Nesta actuación tamén se crearán novos espazos con dotacións, áreas residenciais dunha soa familia e bloques de vivendas, o que aumentará a porcentaxe da poboación da vila respecto á do municipio.

Outra peculiaridade que ter en conta foi o traslado definitivo de todo o persoal do Servizo de Emerxencias de Galicia ás novas instalacións inauguradas na vila da Estrada. Nesta infraestrutura centralízanse todos os servizos do 112 e do 061, dándolle cobertura a todo o territorio galego. Igualmente, cómpre mencionar a continua expansión das actividades dentro da Academia Galega de Seguridade Pública (AGASP), que tamén está na Estrada, ao lado do Servizo de Emerxencias. Nesta academia é onde se forman e reciben cursos continuamente todos os corpos de seguridade: policía autonómica, garda civil o policía municipal. Ademais, conta con servizo de residencia, infraestruturas deportivas, etcétera.

Todo isto redunda nunha conclusión clara: as proxeccións de poboación sinalan que o número de habitantes da vila da Estrada aumentará, no curto e medio prazo, a bo ritmo. Este incremento implica a necesidade de provisión de máis servizos, como os de farmacia, para un número crecente de usuarios.

O municipio da Estrada, e especialmente o seu núcleo urbano, presenta unhas bases territoriais que se poden catalogar como boas, polo que é posible prognosticarlle un futuro esperanzador baseado en todas e cada unha das súas peculiaridades e na propia idiosincrasia deste territorio, en boa medida grazas á aprobación hai catro anos dun Plan Xeral de Ordenación Municipal (PXOM) fronte ás normas subsidiarias que o lexislaron desde 1978. Este plan facilitou a construción do novo centro de saúde, unha nova gardería municipal (o que indica que a Xunta de Galicia coñece a dinámica demográfica do núcleo urbano da Estrada) e mais un centro de día (público-privado). Tamén, grazas ao PXOM, executáronse as comentadas áreas comerciais estratexicamente localizadas nas saídas oeste e leste da vila. A isto hai que engadirlle o impacto que terá a medio e longo prazo a presenza dos empregados e traballadores da Academia Galega de Seguridade e mais da Axencia de Emerxencias de Galicia, pois son dúas infraestruturas e servizos exclusivos da Estrada que non hai en ningún outro lugar de Galicia. De feito, desde diferentes asociacións locais de comerciantes, hostalaría e inmobiliarias, están percibindo o aumento da demanda de servizos de persoas foráneas ao municipio. 


\subsection{Estudio demográfico: presente e proxeccións}

O municipio da Estrada non está exento do agudo e grave proceso de envellecemento demográfico no que se atopa Galicia. Por iso, neste apartado contrastaremos esta realidade e poñeremos o foco de atención na escala parroquial e mais na que afecta á dinámica da poboación máis alá dun determinado limite administrativo, así como saber as consecuencias que terá dentro do obxectivo deste traballo (Bachiller, Gil e Molina de la Torre, 2012; Baraja Rodríguez, 2003; Fernández Fernández, LópezPenabad e Iglesias, 2020; Gómez-Limón, Atance e Rico, 2007; Molinero, 2012; Oliva Denis y Aldrey Vázquez (2018); Vinuesa e Puga, 2007).

Non é necesario retroceder moito para apreciar que o mencionado envellecemento da poboación é unha realidade preocupante. Se retrocedemos ata o 2000, o inicio do século XXI, vemos como o descenso da poboación se repite en todas as escalas, aínda que con advertencias.

En efecto, o descenso de poboación no período do 2000 ao 2017, a escala galega, foi de 23.561 persoas, pero cunha marcada perda a partir do ano 2010. Mentres, a escala provincial, en Pontevedra a poboación aumentou en 30.110 persoas da man das cidades e áreas de influencia de Vigo e das Rías Baixas, pero, como sucedía a escala galega, experimentou un descenso continuo desde 2010.

Nas escalas comarcal e municipal, a perda de poboación é constante desde a chegada do século XXI. Con todo, é moito máis significativa a escala comarcal que municipal, pois a actividade e características socioeconómicas da vila da Estrada sustentan este comportamento. A comarca perdeu 5.549 habitantes, mentres que o municipio da Estrada, 1.617 (ver Figura 3).

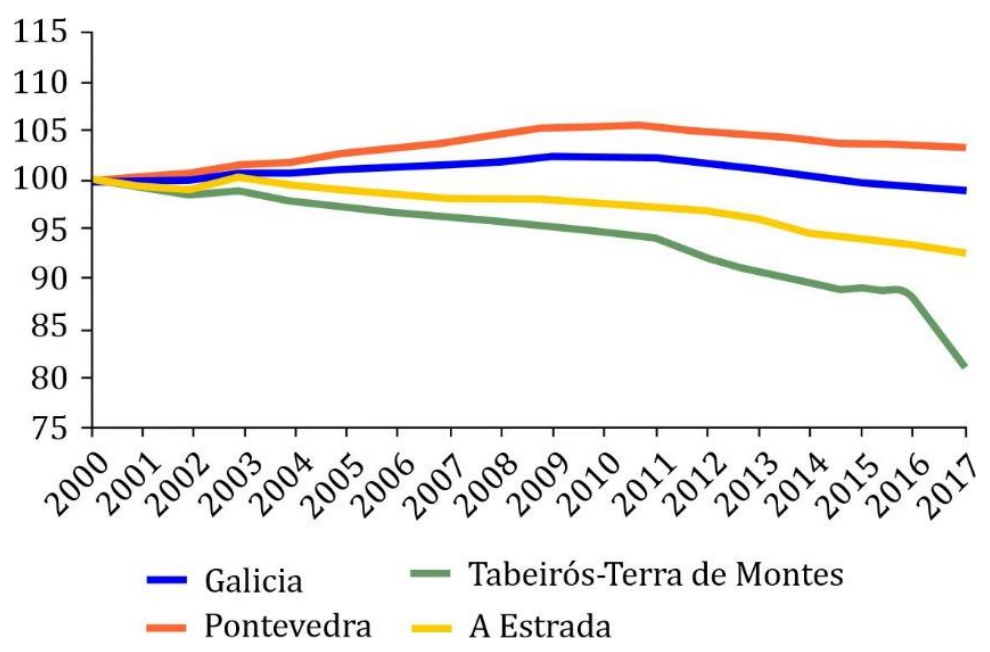

Figura 3. Evolución do número de habitantes en Galicia, na provincia de Pontevedra, na comarca de Tabeirós-Terra de Montes e no municipio da Estrada desde o 2000 ao 2017 (realízase unha gráfica da evolución do número de habitantes desde o ano 2000 ao 2017 en base 100, coa finalidade de comprobar as tendencias das diferentes escalas territoriais nunha mesma gráfica). Fonte: elaboración propia a partir de datos do INE (2018) e do IGE (2018).

Onde si temos un comportamento homoxéneo e de descenso permanente de poboación a calquera escala territorial é nas proxeccións demográficas cara ao 2030. De feito, a escala de toda Galicia, o número de habitante decrecerá en 160.292 persoas, rozando unha poboación total de 2,5 millóns de habitantes.

A provincia de Pontevedra, a pesar de ter varias das áreas máis dinámicas desde o punto de vista socioeconómico do territorio galego, como son a área de influencia da cidade de Vigo, a de Pontevedra ou a das Rías Baixas, tamén descenderá a súa poboación en preto de 50.000 persoas (47.884 segundo 
os datos do IGE (2018)). En último lugar, a comarca de Tabeirós-Terra de Montes tamén perderá poboación, 2.547 persoas. De todos os xeitos, a pesar do comportamento negativo desde o punto de vista demográfico, a perda de poboación non é todo o negativa que se podería esperar dun espazo rural do interior da provincia de Pontevedra. Nesta desaceleración do proceso de perda de poboación, ten moita influencia a propia estrutura socioeconómica da vila da Estrada, que permite dar os servizos públicos e privados a toda a comarca e aos municipios próximos.

Outro indicador interesante é a poboación estacional máxima, que é unha estimación da poboación que pode soportar un municipio. No cálculo inclúense as persoas que teñen algún tipo de vínculo ou relación co municipio, xa sexa porque residen, traballan, estudan ou pasan algún período de tempo nel. Estes datos son publicados polo Ministerio de Hacienda y Administraciones Públicas. No caso da Estrada, na última década do século XX estaba nas 40.000 persoas, pero co descenso demográfico e os procesos de crise como o iniciado no ano 2008, o valor da poboación estacional máxima descendeu. Con todo, apréciase como o descenso é menor ao número absoluto de poboación, como vimos na Figura 3, pois, neste caso, do ano 2000 ao 2016 foi de menos 4.561, non chegando ás 37.000 persoas no ano 2016.

Ao centrarnos no estudo demográfico a escala parroquial, todas as parroquias da Estrada perderon poboación desde o ano 2000 ao 2017, salvo a de San Paio, que se corresponde co núcleo urbano. De feito, as 50 parroquias rurais tiveron en conxunto un descenso demográfico do $12 \%$, mentres que a parroquia urbana aumentou nun 20,4\% no mesmo período de tempo (ver Táboa 1). Neste curto período cronolóxico, en 35 das 50 parroquias rurais houbo un descenso superior ao $20 \%$ da súa poboación, chegando a ter casos parroquiais con perdas de entre un $40 \%$ e un $50 \%$ da poboación, coa agravante de que son entidades de poboación que non chegaban aos 100 habitantes.

Táboa 1. Evolución da poboación das parroquias urbanas e rurais do municipio da Estrada desde o ano 2000 ao 2017

\begin{tabular}{lccc}
\hline Parroquias & 2000 & 2017 & Evolución 2000-2017 \\
\hline Rurais & 16.477 & 13.275 & -2.142 \\
Urbanas & 7.840 & 9.442 & 1.602 \\
Total & 24.317 & 22.717 & -1.600 \\
\hline
\end{tabular}

Fonte: elaboración propia a partir de datos do INE (2018) e do IGE (2018).

En relación co obxectivo deste traballo, e valorando os datos da evolución demográfica das parroquias, detectamos varios factores a ter moi en conta.

No suposto de instalar unha nova farmacia dentro do municipio da Estrada, a única parroquia que sería lóxico que a acollese sería a de San Paio, pois tan só ela é a que ten un constante incremento de poboación. Ademais, as outras variables socioeconómicas que vimos nos apartados anteriores tamén confirman que é, quizais en exclusividade, o espazo que manterá a actividade social e económica deste municipio e da comarca. De feito, o seu crecemento foi continuo: de 7.840 persoas no ano 2000 a 8.757 no 2007 e a 9.442 no 2017, o que supón unha evolución de 1.602 persoas máis na vila da Estrada. Con todo, para nós o incremento e concentración da poboación que "vive" na parroquia de San Paio é moito maior, pois é o destino da actividade comercial, do ocio e dos servizos públicos como educación e sanidade de todo o municipio e da súa área de influencia.

Porén, a parroquia onde está na actualidade a farmacia presenta unha permanente perda de poboación. De feito, neste período do 2000 ao 2017 perdeu 63 habitantes, pasando de 288 a 225. Trátase dunha situación que se mantén en todas as parroquias próximas á de Oca (ver Táboa 2), que en conxunto chegan a perder 433 persoas. 
Táboa 2. Evolución da poboación da parroquia de Oca e contiguas do ano 2000 ao 2017

\begin{tabular}{lcccc}
\hline Parroquias & 2000 & 2007 & 2017 & Evolución 2000-2017 \\
\hline Arnois (San Xiao) & 434 & 394 & 364 & -70 \\
San Miguel de Castro (San Miguel) & 314 & 269 & 251 & -63 \\
Loimil (Santa María) & 240 & 218 & 195 & -45 \\
Oca (Santo Estevo) & 288 & 243 & 225 & -63 \\
Orazo (San Pedro) & 376 & 346 & 279 & -97 \\
Remesar (San Cristovo) & 165 & 138 & 121 & -44 \\
Riobó (San Martiño) & 249 & 227 & 198 & -51 \\
\hline
\end{tabular}

Fonte: elaboración propia a partir de datos do INE (2018) e do IGE (2018).

Polo tanto, desde o punto de vista demográfico, non parece que o servizo que dá esta farmacia na actualidade sexa moi significativo dentro do municipio nin que teña un futuro moi positivo nin cubra as necesidades farmacéuticas que debería, ou podería, nun espazo onde o número de persoas cada vez é menor. E isto co factor negativo engadido de que moitas destas parroquias teñen outra farmacia a unha distancia bastante razoable.

\subsection{Análise da localización da oficina de farmacia: actual e proposta}

O estudo da caracterización territorial péchase cunha análise dobre de localización territorial. En primeiro lugar, avaliamos as peculiaridades da localización actual da farmacia e, en segundo lugar, as características da nova proposta de localización. Os resultados deste apartado, unidos aos anteriores, son fundamentais para botar luz no diagnóstico sobre a valoración territorial do traslado da oficina de farmacia.

\subsubsection{Localización actual}

En canto á localización actual da farmacia, consideramos unha debilidade o seu emprazamento na parroquia de Oca. Trátase dunha edificación illada, á que é preciso ir nun medio de locomoción e que non ten entidades de poboación concentradas, senón vivendas diseminadas. A farmacia non queda nunha aldea, nun núcleo rural de poboación, senón que está radicada nun agrupamento disperso de casas.

Outra debilidade clara é que está a unha distancia de 1,6 km do Centro de Saúde de Oca, a 24 minutos a pé, pois non existe un camiño adecuado para peóns e incluso hai que cruzar a AP-53. 0 mesmo acontece para o resto dos habitantes da parroquia e dos arredores, xa que a farmacia non está asentada en ningunha entidade de poboación. De feito, unha das características que lle cómpre a un servizo sanitario para a poboación é a complementariedade entre os servizos médicos e os farmacéuticos, e máis aínda ao tratarse dunha área rural onde predomina a poboación vella que, despois de desprazarse ao Centro de Saúde, debera poder ir andando, cunhas mínimas condicións de accesibilidade, ata a oficina de farmacia.

O desprazamento en automóbil supón moito menos tempo, pero non deixa de ser sumamente incómodo para as persoas que visitan o Centro de Saúde. En efecto, unha vez que saen do Centro de Saúde e collen de novo o coche, se queren ir á farmacia teñen que incorporarse a unha estrada nacional, a N-525, para ao pouco saír dela. Deste xeito, xorde o inconveniente de que, se as persoas ao saír do Centro de Saúde de Oca continúan por esa mesma estrada en dirección a Silleda, teñen unha farmacia a 9 minutos no lugar de Bandeira, e sen necesidade de desviarse da estrada nacional. Sucede exactamente o mesmo se continúan pola N-525 en dirección a Santiago de Compostela, pois a tan só 6 minutos do Centro de Saúde hai unha farmacia en Santa Cruz de Ribadulla (Vedra). Incluso as persoas que vaian en 
dirección ao núcleo da Estrada atoparán a 10 minutos, na estrada N-640, unha farmacia na parroquia de Rubín, no lugar do Foxo (ver Táboa 3). Por outra banda, consideramos que, desde o punto de vista da estratexia territorial, a farmacia deo Foxo posúe a potencialidade de cubrir a posible demanda de servizos farmacéuticos de todo o nordeste do municipio estradense.

Táboa 3. Distancia en metros e en minutos en coche desde o Centro de Saúde ata as farmacias das proximidades

\begin{tabular}{lcc}
\hline Nome & Distancia (metros) & Tempo (minutos) \\
\hline Farmacia de Oca (A Estrada) & 1.600 & 3 \\
Farmacia Ramón Varela (Vedra) & 5.600 & 6 \\
Farmacia Silva (Silleda) & 8.700 & 9 \\
Farmacia O Foxo (A Estrada) & 8.000 & 10 \\
\hline
\end{tabular}

Fonte: elaboración propia a partir de datos facilitados por Google Maps no ano 2019.

En definitiva, ao comprobar os tempos a que se atopan as diferentes farmacias do Centro de Saúde de Oca, no caso de trasladar a farmacia para o núcleo da Estrada, todos os habitantes da contorna terían, nun raio de 10 minutos, tres oficinas de farmacia nas beiras das estradas nacionais e con áreas de aparcamentos habilitadas. Polo tanto, consideramos que co traslado quedaría ben cuberto o servizo farmacéutico. Ademais, todas as persoas que viven nesta área do municipio da Estrada teñen que usar o automóbil para cubrir as súas necesidades diarias (Administración, educación, comercio o alimentación en grandes superficies, por citar só algunhas delas), polo que non cabe, en ningún caso, falar de desatención farmacéutica dos habitantes de Oca.

Unha característica territorial que non afecta só ás variables de localización, xa mencionada en varias ocasións, é a mobilidade da poboación, e máis nun espazo rural onde os servizos están concentrados en determinadas áreas urbanas, como é o núcleo da Estrada. En efecto, a poboación realiza desprazamentos diarios (movementos pendulares) buscando o percorrido óptimo que cubra as súas demandas. Polo tanto, a poboación non ten que respectar límites administrativos ou áreas te-rritoriais farmacéuticas, senón que se desprazará á farmacia que lles quede máis preto do seu domicilio, do seu centro de saúde ou, se é o caso, na ruta que adoito realiza para completar as súas necesidades.

\subsubsection{Localización proposta}

Polo que respecta á nova localización que se propón para a oficina de farmacia na parroquia de San Paio, esta posúe varios aspectos que se poden catalogar como positivos, pensando no posible servizo farmacéutico que lle podería ofertar á poboación.

En primeiro lugar, tendo en conta as características de mobilidade da poboación das parroquias do rural da Estrada e doutras de municipios adxacentes que realizan desprazamentos diarios ao núcleo da Estrada, o establecemento dunha nova farmacia nesta área do núcleo urbano considerámolo un feito moi positivo. É máis, este espazo da área leste do núcleo urbano estradense é unha das máis dinámicas desde o punto de vista socioeconómico e onde se están a realizar unha serie de construcións e infraestruturas. Entre elas destacan, ademais da creación dun Centro de Saúde, a recente construción dunha nova gardería e a renovación das instalacións da Casa da Música, que alberga o Conservatorio de Música municipal e varias bandas e asociacións de música. Nesta área tamén están as instalacións dos museos municipais e hai xa proxectado o desenvolvemento dunha nova área comercial, infraestruturas, todas elas, que axudaran a aglutinar un maior volume de poboación nesta contorna do núcleo da Estrada. En segundo lugar, e independentemente da obrigatoria necesidade de cumprir coa normativa vixente no relativo ás distancias das farmacias de nova apertura ou traslado con respecto aos centros 
de saúde, no caso concreto da Estrada consideramos que é preciso aproximar, na medida do posible, unha farmacia a este espazo. Este sería o modo de aproveitar todas as potencialidades e servizos que ofrecerá o novo Centro de Saúde, xa que a maioría da poboación que se traslade a el o fará en automóbil, coa vantaxe de que alí disporán dunhas óptimas zonas de aparcamento. Desta maneira, unha vez estacionado o vehículo, poderán acudir camiñando tanto ao Centro de Saúde como á farmacia e, así, ter cubertas as súas necesidades sanitarias (ver Figura 4).

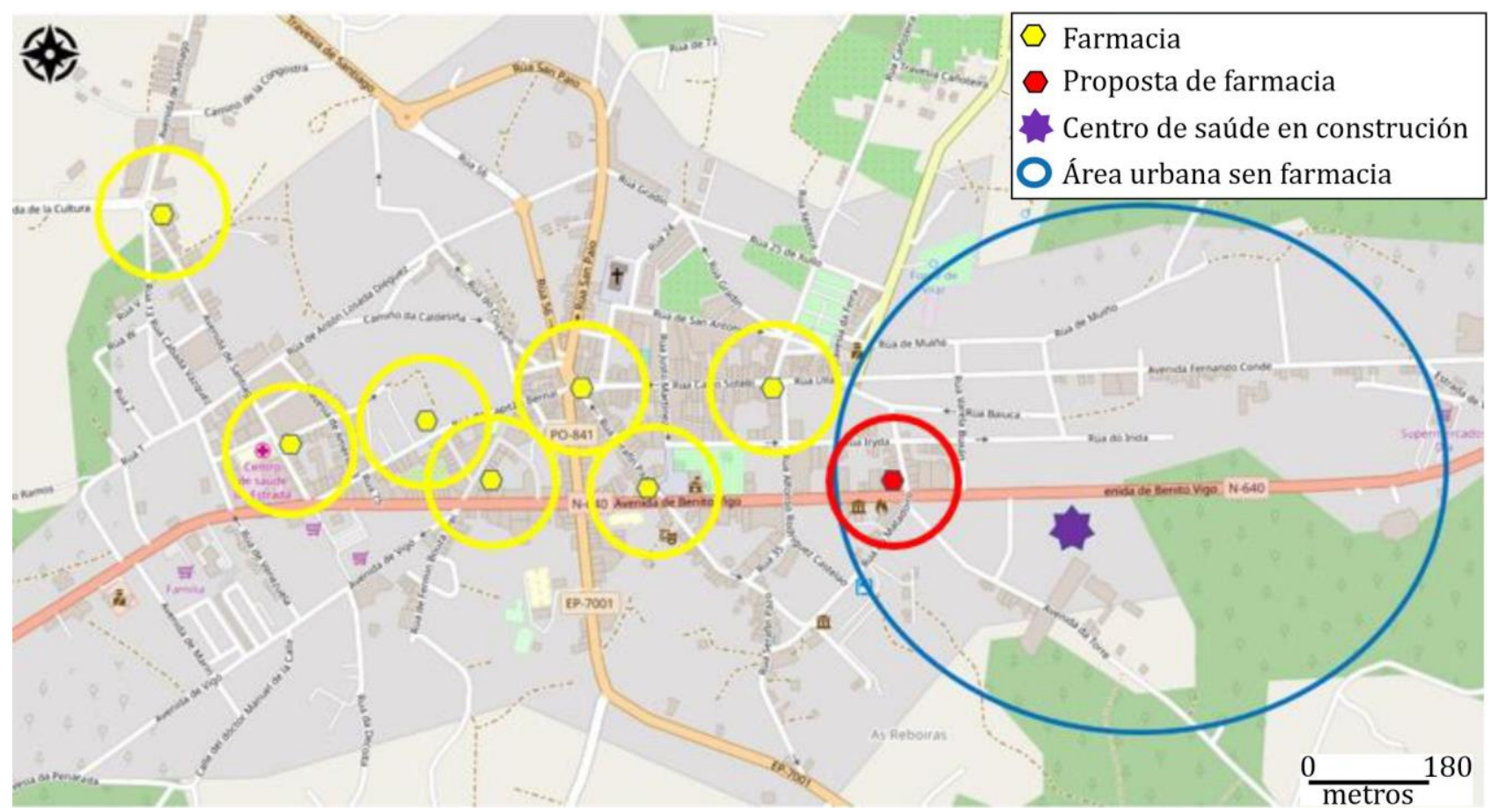

Figura 4. Localización territorial das farmacias do núcleo urbano da Estrada, do Centro de Saúde en construción e a situación da proposta de traslado de farmacia. Fonte: elaboración propia a partir de datos facilitados por GeaMap no 2019.

Tal e como amosamos na Táboa 4, as farmacias máis próximas ao novo Centro de Saúde están a unha distancia en tempo a pé de 10 minutos, aproximadamente, isto é, de 500 a 800 metros. Esta distancia pode parecer pequena pero, ao facer o desprazamento de ida e volta ata onde se deixou o coche unha vez recibida a consulta médica, pode transformarse nun traxecto demasiado longo para persoas enfermas, con mobilidade reducida ou invalidez.

Táboa 4. Distancia en metros e minutos camiñando desde o novo Centro de Saúde ás farmacias do centro urbano da Estrada

\begin{tabular}{lcc}
\hline Nome & Distancia (metros) & Tempo (minutos) \\
\hline Farmacia Madriñán & 500 & 7 \\
Farmacia Eirín & 600 & 8 \\
Farmacia Fenollera & 800 & 10 \\
Farmacia Durán & 900 & 12 \\
Farmacia Outón & 1.000 & 14 \\
Farmacia Losada & 1.200 & 16 \\
Farmacia Rodríguez & 1.600 & 21 \\
\hline
\end{tabular}

Fonte: elaboración propia a partir de datos facilitados por Google Maps no 2019. 
Esta distancia aumenta para aquelas persoas que se despracen desde a nova área de expansión comercial en desenvolvemento. Ademais, segundo a documentación municipal, moitas das parcelas contiguas ao novo Centro de Saúde son de titularidade municipal, e nun período curto de tempo posiblemente sexan cedidas á Administración autonómica para a construción dos novos xulgados do partido xudicial e outros servizos públicos como unha residencia de anciáns.

\section{Discusión de resultados}

Neste apartado faise mención unicamente ao estudo do caso analizado, sen incluílo nun contexto internacional ou noutro ámbito científico. Deste xeito, centrámonos en discutir sobre os resultados obtidos e sobre calquera outra información producida pola nosa investigación que nos permita darlle resposta ao noso obxectivo, como paso preliminar ao desenvolvemento das conclusións.

0 mellor modo de contrastar os resultados da nosa valoración territorial sobre a proposta de traslado da oficina de farmacia é mediante unha sucesión de puntos, coa conseguinte reflexión tras a análise dos diferentes datos e mais das realidades socioeconómicas do territorio que nos preocupa. Este apartado segue a mesma estrutura dos contidos do artigo.

Desde o punto de vista da súa caracterización territorial, no municipio da Estrada existe un claro dualismo entre a evolución socioeconómica da parroquia de San Paio, onde está o núcleo urbano, e o resto das parroquias. Por un lado, a vila da Estrada cada vez concentra máis servizos públicos e privados, aumentando o número de habitantes, fronte ao resto das parroquias, que perden poboación. Existe un feito que consideramos clave neste proceso de dinamismo actual e futuro: a aprobación do PXOM. Ata hai catro anos, o municipio da Estrada tiña a súa ordenación do territorio "dirixida" legalmente por unhas normas subsidiarias do ano 1978. En consecuencia, desde que ten unha lexislación territorial actual, a vila da Estrada está resolvendo demandas do pasado, como son a creación de novas vivendas, unha nova gardería municipal (a Xunta de Galicia non executaría este investimento se non tivese previsto que o servizo xa estaba cuberto), un novo centro de saúde ou as novas áreas comerciais.

Desde hai pouco, xa están a pleno funcionamento a Academia Galega de Seguridade Pública, espazo para os profesionais das emerxencias, protección civil e seguridade de Galicia, así como a Axencia Galega de Emerxencias (AXEGA), un ente instrumental encargado do estudo e da execución política autonómica en materia de protección civil e de xestión de emerxencias. Xa que logo, o núcleo da Estrada está recibindo o desprazamento de todas aquelas persoas que traballan nestes centros, así como daquelas que demandan parte dos seus servizos formativos, reunións... Estes profesionais xeran unha serie de beneficios económicos no comercio e na hostalería estradense. Ademais, existen previsións de que algúns destes individuos acabe desprazándose definitivamente ao núcleo urbano da Estrada por motivos laborais.

No que concirne estritamente aos servizos de saúde, hoxe en día na vila da Estrada atópase un único Punto de Atención Continuada do territorio, a onde se deben desprazar os veciños de todas as parroquias fóra dos horarios comúns de apertura dos centros de saúde. Trátase dun desprazamento perfectamente asumido pola centralidade e a accesibilidade da vila.

No tocante á análise da localización, a situación actual da oficina de farmacia de Oca presenta unha serie de debilidades moi claras. En primeiro lugar, está illada, fóra de calquera asentamento de poboación que asegure o desprazamento camiñando dun número mínimo de poboación á farmacia. En segundo lugar, aínda que próxima en distancia ao Centro de Saúde de Oca, en canto ao tempo camiñando está moi mal comunicada, case inviable, sendo "obrigatorio" o uso do automóbil. En terceiro lugar, para chegar á farmacia cómpre empregar algún medio de locomoción, o que enlaza con outra debilidade, como é a competencia das oficinas próximas doutros municipios que están moito mellor localizadas nas beiras dunha estrada nacional como é a N-525.

Facemos fincapé en destacar a competencia que soporta a farmacia de Oca por parte das farmacias dos municipios de Silleda e de Vedra, pois estas quedan a unha distancia similar (en coche) e moito 
máis próximas que as do núcleo urbano da Estrada. Porque o que debemos de ter claro é que as persoas, ao saír do Centro de Saúde de Oca, pensan en que farmacia lles queda de camiño, sen importarlles en que municipio se atope. Dentro da localización territorial estratéxica das oficinas de farmacia do municipio da Estrada, consideramos que é moito mellor a situada no Foxo, na parroquia de Rubín, pois non ten outras a pouca distancia e está á beira dunha estrada nacional.

En canto á localización da proposta de traslado da farmacia, parécenos moi adecuada a fin de cubrir a demanda segura que xurdirá no curto e medio prazo. En efecto, como representamos na Figura 3, na área leste do núcleo urbano da Estrada non hai ningunha farmacia e, ademais do novo Centro de Saúde, desenvolverase unha área comercial, acábase de inaugurar unha gardería e están previstas outras actuacións urbanísticas.

$\mathrm{Na}$ actualidade, as sete farmacias da vila da Estrada están localizadas nas áreas central, norte e oeste. 0 traslado da farmacia á Avenida Benito Vigo permitiría que o servizo sanitario fose máis completo para as persoas que teñan consulta médica no novo Centro de Saúde, sen necesidade de empregar o automóbil ou de percorrer unha distancia considerable camiñando, así como favorecer o aproveitamento da infraestrutura e dos servizos do novo Centro de Saúde, principalmente as áreas de aparcamento de doado acceso.

O estudo demográfico confírmanos que o envellecemento demográfico non é unha realidade única do municipio da Estrada. Porén, isto non significa que se vaian producir as actuacións pertinentes para solucionalo. De todos os xeitos, a vila da Estrada é a excepción das 51 parroquias do municipio da Estrada, polo que, no caso de crear ou trasladar unha farmacia, a parroquia de San Paio debería de ser o lugar escollido.

De entre as farmacias do rural estradense, aquelas que se atopan fóra da vila da Estrada, a que ten menos poboación é a de Oca, con 225 habitantes, fronte ás 310 de San Xurxo de Vea e ás 377 de Codeseda. Polo tanto, desde o punto de vista demográfico non ten moito sentido manter unha farmacia nesta área do municipio, aínda que si se debera manter un dispensario, un gabinete de medicina de farmacia.

\section{Conclusións}

Co obxectivo común de realizar a valoración territorial das consecuencias que tería na poboación do municipio da Estrada o traslado dunha oficina de farmacia dunha parroquia a outra, tras a realización dun informe pericial e mais do presente artigo científico, consideramos que se trata dun traslado positivo para o municipio, se ben cun par de condicionantes.

En primeiro lugar, hai que reiterar que existe unha normativa exclusiva sobre a creación e o traslado de oficinas de farmacia, seguindo uns criterios establecidos de poboación e de distancias, que coñecemos e respectamos. Así e todo, neste caso parece que tales criterios non se adecuán ás características territoriais deste municipio do interior da provincia de Pontevedra. De aí, a necesidade de amosar a capacidade de análise da Xeografía para ofrecerlle un mellor servizo á poboación, neste caso un servizo sociosanitario, farmacéutico. Por último, aclaramos que, independentemente da resolución final que se aplique desde a xustiza, estaremos atentos e intentaremos analizar as consecuencias desta resposta xudicial en próximas investigacións. Igualmente, confirmamos o noso interese en analizar a realidade territorial do mapa farmacéutico a outras escalas, como a de Comunidade Autónoma e a de toda España.

En segundo lugar, avogamos por que se manteña un gabinete de medicina de farmacia para a escasa poboación da parroquia de Oca, aínda que sexa por un tempo limitado. De feito, como comprobamos, o número de habitantes en poucas décadas será moi reducido. Este descenso demográfico pode supoñer, incluso, o futuro peche do Centro de Saúde. Esa debera ser a referencia temporal. Mentres exista o Centro de Saúde, debería manterse o gabinete de medicina de farmacia. Dese xeito, a poboación desa parroquia rural non perdería un servizo sanitario que tivo nas últimas décadas. 
Para rematar, queremos facer fincapé en destacar que a Xeografía Aplicada constitúe unha ferramenta de análise territorial sumamente potente e incluso, atrevémonos a dicir, única fronte a outras disciplinas que non teñen en conta todas estas variables presentes nas nosas investigacións desde a Xeografía. Este traballo, entre outros, serve como exemplo da implicación diaria e da capacidade para solucionar conflitos territoriais que pode e debe ter a Xeografía Aplicada na sociedade actual no seu máis amplo sentido (localización de servizos, infraestruturas, industrias, entre otros), neste caso, relacionada coa Xeografía da Saúde, así como evidenciar a súa afinidade e coincidencia de intereses coa Economía.

\section{Bibliografía}

Agbonifo, P. O. (1983). The state of health as a reflection of the level of development of a nation. Social Science and Medicine, 17(24), 2003-2006. DOI: https://doi.org/10.1016/0277-9536(83)90140-5

Bachiller, J. M., Gil, E., e Molina de la Torre, I. (2012). Los centros comarcales de servicios. En J. M. Delgado Urrecho (Dir.), Población y poblamiento en Castilla y León (pp. 811-968). Valladolid: Consejo Económico y Social de Castilla y León. Recuperado de: http://uvadoc.uva.es/handle/10324/9066

Bailly, A., e Périat, M. (1995). Médicométrie. Une nouvelle aproche de la santé. Paris, France: Económica. DOI: https://doi.org/10.7202/022611ar

Banister, D. (2011). The trilogy of distance, speed and time. Journal of Transport Geography, 19(4), 950-959. DOI: https://doi.org/10.1016/j.jtrangeo.2010.12.004

Baraja Rodríguez, E. (2003). La despoblación, un fenómeno demográfico todavía vigente en Castilla y León. En F. García Pascual (Coord.), La lucha contra la despoblación todavía necesaria. Políticas y estrategias sobre la despoblación rural en el siglo XXI (pp. 105-126). Zaragoza: Centro de Estudios sobre la Despoblación y el Desarrollo de Áreas Rurales (CEDDAR). Recuperado de: https://dialnet.unirioja.es/servlet/libro?codigo=3076

Barredo, J. (1997). Aplicación de técnicas de análisis espacial integrando evaluación multicriterio y sistemas de información geográfica para la realización de estudios de localización/asignación de actividades. Alcalá de Henares: Universidad de Alcalá de Henares.

Recuperado de: https://dialnet.unirioja.es/servlet/libro?codigo=113902

Bosque, J., e Franco, S. (1995). Modelos de localización-asignación y evaluación multicriterio para la localización de instalaciones no deseables. Serie Geográfica, 5, 97-114.

Recuperado de: https://core.ac.uk/download/pdf/58902313.pdf

Bosque, J., e Moreno, A. (2004). Sistemas de información geográfica y localización óptima de instalaciones y equipamientos. Madrid: RA-MA.

Recuperado de: https://www.ra-ma.es/libro/sistemas-de-informacion-geografica-y-localizacion-optima-deinstalaciones-y-equipamientos $48455 /$

Carver, S. J. (1991). Integrating multicriteria evaluation with geographical information systems. International Journal of Geographical Information Systems, 5(3), 321-339.

DOI: https://doi.org/10.1080/02693799108927858

Christaller, W. (1933). Die Zentralen Orte in Süddeutschland. Jena, Germany: Gustav Fischer Verlag.

Comber, A. J., Brunsdon, C., e Radburn, R. (2011). A spatial analysis of variations in health access: Linking geography, socio-economic status and access perceptions. International Journal of Health Geographics, 10, 44. DOI: https://doi.org/10.1186/1476-072X-10-44

Consejo General de Colegios Oficiales de Farmacéuticos. (2019). Estadísticas de colegiados y farmacias comunitarias 2017. Madrid: Consejo General de Colegios Oficiales de Farmacéuticos.

Recuperado de: https://www.portalfarma.com/

Cooke, P. (1985). Class practices as regional markers: A contribution to labour geography. En D. Gregory e J. Urry (Eds.), Social relations and spatial structures (pp. 213-241). London, UK: MacMillan.

DOI: https://doi.org/10.1007/978-1-349-27935-7_10

Crooks, V. A., Andrews, G. J., e Pearce, J. (2018). Routledge Handbook of Health Geography. London, UK: Routledge Handbook Online.

Recuperado de: https://www.routledge.com/Routledge-Handbook-of-Health-Geography/Crooks-AndrewsPearce/p/book/9781138098046

Davies, B. P. (1968). Social needs and resources in local services: A study of variations in provision of social services between local authority areas. London, UK: Joseph Rowntree. Recuperado de: https://kar.kent.ac.uk/27434/ 
Farmaconsulting. (2019). https://www.farmaconsulting.es/

FarmaQuatrium (2019). https://www.farmaquatrium.es/

Fernández Fernández, M., López-Penabad, M.-C., e Iglesias Casal, A. (2020). Socio-economic challenges of demographic change. Revista Galega de Economía, 29(2), 1-3.

Retrieved from: https://revistas.usc.gal/index.php/rge/article/view/7177

Ferraz, A. C. P., e Torres, I. G. E. (2004). Transporte público urbano. (2ª ed.). São Carlos, Brasil: Rima.

Fujita, M., e Krugman, P. (2004). The new economic geography: Past, present and the future. En R. J. G. M. Florax e D. A. Plane (Eds.), Fifty years of regional science. Advances in spatial science (pp. 239-164) Berlin, Heidelberg, Germany: Springer. Recuperado de: https://doi.org/10.1007/978-3-662-07223-3_6

Garb, J. L., e Wait, R. B. (2011). Using spatial analysis to improve health care services and delivery at baystate health. Journal of Map \& Geography Libraries, 7(3), 190-208. DOI: https://doi.org/10.1080/15420353.2011.599768

Gatrell, A. C. (1998). Structures of geographical and social space and their consequences for human health. Geografiska Annaler: Series B, Human Geography, 79(3), 141-154. DOI: https://doi.org/10.1111/i.0435-3684.1997.00014.x

Gatrell, A. C. (2002). Geographies of health: An introdution. Oxford, UK: Blackwell.

GeaMap. (2019). http://www.geamap.com/

Gesler, W. M., e Kearns, R. A. (2002). Culture/Place/Health. London, UK: Routledge. DOI: https://doi.org/10.4324/9780203996317

Gilbert, A. (1988). The new regional geography in English and French-speaking countries. Progress in Human Geography, 12(2), 208-228. DOI: https://doi.org/10.1177/030913258801200203

González Pérez, J. M. (2001). La demanda de una verdadera ordenación territorial sanitaria en Galicia. Desarrollo actual del mapa de salud: ¿cuándo y para qué? Boletín de la Asociación de Geógrafos Españoles, 29, 29-51. Recuperado de https://dialnet.unirioja.es/servlet/articulo?codigo=1318661

Gómez-Limón, J. A., Atance, I., e Rico, M. (2007). Percepción pública del problema de la despoblación del medio rural en Castilla y León. Ager. Revista de Estudios sobre Despoblación y Desarrollo Rural, 6, 9-60. Recuperado de: https://dialnet.unirioja.es/servlet/articulo?codigo $=2515508$

Googlemaps. (2019). https://www.google.com/maps

Gould, P. (1993). The slow plague: A geography of the AIDS pandemic. Oxford, UK: Blackwell. DOI: https://doi.org/10.1177\%2F030913259401800222

Graham, H. (Ed.). (2000). Understanding health inequalities. Buckingham, UK: Open University Press.

Harvey, D. (1973). Social Justice, and the City. London, UK: Edward Arnold. DOI: https://doi.org/10.1017/S0047279400001094

Haynes, R. (2016). The geography of health services in Britain. London, UK: Routledge.

Howe, G. M. (1977). A world geography of human diseases. London, UK: Academic Press.

Hunter, J. M. (1974). The geography of health and disease. Chapel Hill, NC: University of North Carolina.

Instituto Galego de Estatística. (2018). Padrón Municipal de Habitantes. Santiago de Compostela: IGE. Recuperado de: https://www.ige.eu/web/mostrar actividade estatistica.jsp?idioma=gl\&codigo=0201001002

Instituto Galego de Estatística. (2019). Padrón Municipal de Habitantes. Santiago de Compostela: IGE. Recuperado de: https://www.ige.eu/web/mostrar actividade estatistica.jsp?idioma=gl\&codigo=0201001002

Instituto Nacional de Estadística. (2018). Cifras de población y Censos demográficos. Madrid: INE. Recuperado de: https://www.ine.es/dyngs/INEbase/es/categoria.htm?c=Estadistica P\&cid=1254734710984

Isard, W. (1956). Location and space economy. Cambridge, MA: The MIT Press.

Janssen, R., e Rietveld, P. (1990). Multicriteria analysis and geographical information systems: An application to agricultural land use in the Netherlands. En H. Scholten e J. Stivell (Eds.), Geographical information systems for urban and regional planning (pp. 129-139). Dordrecht, Netherlands: Kluwer.

DOI: https://doi.org/10.1007/978-94-017-1677-2 12

John Snow Society. (2020). www.johnsnowsociety.org

Jones, K., Gould, M. I., e Duncan, C. (2000). Death and deprivation: An exploratory analysis of deaths in the Health and Lifestyle Survey. Social Science and Medicine, 50(7-8), 1059-1079.

DOI: http://doi.org/10.1016/S0277-9536(99)00355-X

Jones, K., e Moon, G. (1987). Health, disease and society: An introduction to medical geography. London, UK: Routledge \& Kegan Paul. Recuperado de:

https://www.researchgate.net/publication/234015155 Health Disease and Society A Critical Medical Geo graphy 
Joseph, A. E., e Phillips, D. R. (1984). Accessibilty \& utilization. Geographical perspectives on health care delivery. London, UK: Harper \& Row. Recuperado de: https://researchers.mq.edu.au/en/publications/accessibility-and-utilization-geographical-perspectives-onhealth

Kleindorfer, D., Xu, Y., Moomaw, C. J., Khatri, P., Adeoye, O., e Hornung, R. (2009). US geographic distribution of rt-PA utilization by hospital for acute ischemic stroke. Stroke, 40(11), 3580-3584. DOI: http://doi.org/10.1161/STROKEAHA.109.554626

Knox, P. L. (1975). Social well-being: A spatial perspective. Oxford, UK: Oxford University Press.

Knox, P. L. (1978). The intraurban ecology of primary medical care: Patterns of accessibility and their policy implications. Environment and Planning A, 10(4), 415-435. DOI: https://doi.org/10.1068\%2Fa100415

Knox, P. L. (1979). Medical deprivation, area deprivation and public policy. Social Science and Medicine, 13(2), 111-121. DOI: https://doi.org/10.1016/0160-8002(79)90057-1

Kravitz, R. L., Paterniti, D. A., Epstein, R. M., Rochlen, A. B., Bell, R. A., Cipri, C., Fernández y García, E., Feldman, M. D., e Duberstein, P. (2011). Relational barriers to depression help-seeking in primary care. Patient Education and Counseling, 82(2), 207-213. DOI: https://dx.doi.org/10.1016\%2Fj.pec.2010.05.007

Krugman, P. (1992). Geografía y comercio. Barcelona: Antoni Bosch.

Lewis, N. D., e Mayer, J. D. (1988). Disease as natural hazard. Progress in Human Geography, 12(1), 15-33. DOI: https://doi.org/10.1177\%2F030913258801200102

Ley 16/1997, de 25 de abril, de Regulación de Servicios de las Oficinas de Farmacia. Legislación consolidada. Jefatura del Estado. Boletín Oficial del Estado, 100, de 26 de abril de 1997. Referencia: BOE-A-1997-9022. Recuperado de: https://www.boe.es/buscar/act.php?id=BOE-A-1997-9022

Ley 3/2019, de 2 de julio, de Ordenación Farmacéutica de Galicia. Diario Oficial de Galicia, 130, de 10 de julio de 2019. Recuperado de: https://www.xunta.gal/dog/Publicados/2019/20190710/AnuncioC3B0-050719-0001_es.html

Lois, R. C. (1993). Problemas para a delimitación dos espazos urbanos e rurais. En Asociación Galega de Historiadores, Concepcións espaciais e estratexias na Historia de Galicia (pp. 201-223). Santiago de Compostela: Tórculo. Recuperado de: https://dialnet.unirioja.es/servlet/libro?codigo=446571

Lois, R. C. (2005). Desenvolvemento e planeamento urbanos en Galicia. En M. A. Fernández (Coord.), Planificación do territorio, urbanismo e educación ambiental (pp. 15-41). Santiago de Compostela: Universidade de Santiago de Compostela, Servizo de Publicacións e Intercambio Científico.

Lösch, A. (1940). Die Räumliche Ordnung der Wirtschaft. Jena, Germany: Gustav Fischer Verlag.

Massey, D. (1984): Spatial divisions of labour: Social structures and the geography of production. London, UK: MacMillan. DOI: http://dx.doi.org/10.4135/9781446213742.n10

Massey, D. (1990). L' «estudi de localitats» en Geografia Regional. Treballs de la Societat Catalana de Geografia, 21,73-87. Recuperado de: https://publicacions.iec.cat/repository/pdf/00000081/00000074.pdf

Mayhew, L. (2018). Urban hospital location. London, UK: Routledge. Recuperado de: https://www.researchgate.net/publication/326010380 Urban Hospital Location

Mayhew, L. D., e Leonardi, G. (1984). Resource allocation in multilevel spatial health care systems. En M. Clarke (Ed.), Planning and analysis in Health Care Systems (pp. 194-209). London, UK: Pion. Recuperado de: https://www.researchgate.net/publication/328718641 Resource allocation in multilevel_spatial health car e systems

McAllister, D. M. (1976). Equity and efficiency in public facility location. Geographical Analysis, 8, 47-63. DOI: http://dx.doi.org/10.1111/i.1538-4632.1976.tb00528.x

McLaren, Z., Ardington, C., e Leibbrandt, M. (2013). Distance as a barrier to health care access in South Africa. Working Paper Series, 97. Cape Town, Southern Africa: South Africa Labour and Development Research Unit. Recuperado de: https://econpapers.repec.org/scripts/redir.pf?u=http\%3A\%2F\%2Fwww.opensaldru.uct.ac.za\%2Fbitstream \%2Fhandle\%2F11090\%2F613\%2F2013 97.pdf\%3Fsequence\%3D1;h=repec:ldr:wpaper:097

Miramontes Carballada, A. (2016). Reseña bibliográfica de A Galicia urbana. Revista Galega de Economía, 25(1), 183-184. Recuperado de: https://revistas.usc.gal/index.php/rge/article/view/3039

Mohan, J. (1988). Restructuring privatization and the geography of health care provision in England, 1983-1987. Transactions of the Institute of British Geographers, 13(4), 449-465. DOI: http://doi.org/10.2307/622741

Moïsi, J. C., Nokes, D. J., Gatakaa, H., Williams, T. N., Bauni, E., Levine, O. S., e Scott, J, A. G. (2011). Sensitivity of hospital-based surveillance for severe disease: A geographic information system analysis of access to care in Kilifi district, Kenya. Bulletin of the World Health Organization, 89, 102-111.

DOI: http://doi.org/10.2471/BLT.10.080796 
Molinero, F. (2012). Las intensas transformaciones del mundo rural castellano-leonés: la marcha hacia el cuarto paradigma de desarrollo rural. En J. M. Delgado Urrecho (Dir.), Población y poblamiento en Castilla y León (pp. 557-636). Valladolid: Consejo Económico y Social de Castilla y León.

Recuperado de: http://uvadoc.uva.es/handle/10324/9066

Morrill, R. L. (1974). The spatial organisation of society. Belmont, MA: Duxburg Press.

Morrill, R. L., e Erickson, R. J. (1970). Priest factors influencing distances traveled to hospitals. Economic Geography, 46(2), 161-172.

Navarro, V. (1976). Medicine under capitalism. New York, NY: Prodist.

Oliva Denis, R. D., y Aldrey Vázquez, J. A. (2018). Patróns de distribución territorial da poboación estranxeira en Galicia, 1997-2017. Revista Galega de Economía, 27(2), 49-60.

Recuperado de: https://revistas.usc.gal/index.php/rge/article/view/5657

Pacione M. (Ed.) (1986). Medical geography: Progress and prospect. London, UK: Routledge.

Paul, G.K. (1985). Approaches to Medical Geography: An historical perspective. Social Science and Medicine, 20(4), 399-409. DOI: https://doi.org/10.1016/0277-9536(85)90015-2

Pereira, J. M. C., e Duckstein, L. (1993). A multiple criteria decision-making approach to GIS-based land suitability evaluation. International Journal of Geographical Information Systems, 7(5), 407-424.

DOI: https://doi.org/10.1080/02693799308901971

Price, D. G., e Blair, A. M. (1989). The changing geography of the service sector. Hoboken, NJ: Wiley-Blackwell.

Precedo, A. J. (1974). Galicia: red urbana y desarrollo regional. Boletín de la Real Sociedad Geográfica, 110, 161-220. Madrid: Real Sociedad Geográfica.

Precedo, A. J. (1987). Galicia: estructura del territorio y organización comarcal. Santiago de Compostela: Xunta de Galicia.

Pyle, G .F. (1980). New directions in medical geography. Oxford, UK: Pergamon Press.

Pyle, G. F. (1986). The diffusion of influenza: Patterns and paradigms. London, UK: Rowman \& Littlefield.

Barcellos, C., e Santos, S. M. (Eds.). (2006). Abordagens espaciais na saúde pública. (Serie Capacitação e actualização em geoprocessamento em saúde, volume 1). Brasília, Brasil: Ministério da Saúde/Fundação Oswaldo Cruz. Recuperado de: http://bvsms.saude.gov.br/bvs/publicacoes/serie geoproc vol 1.pdf

Rodríguez, R. (1997). La urbanización del espacio rural en Galicia. Barcelona: Oikos-Tau.

Rodríguez, R. (1999). De aldeas a ciudades. Vigo: Ir Indo.

Santana, A. P. (1995). Acessibilidade e utilização dos serviços de saúde. Ensaio metodológico em geografia da saúde. (Tese de doutoramento em Letras (Geografia Humana)). Coimbra, Portugal: CCRC/ARSC. Recuperado de: http://hdl.handle.net/10316/631

Santana, A. P. (2005). Geografias da saúde e do desenvolvimento. Evolução e tendências em Portugal. Coimbra, Portugal: Almedina.

Scott, A. J. (1970). Location-Allocation systems: A review. Geographical Analysis, 2(2), 95-119.

DOI: http://doi.org/10.1111/j.1538-4632.1970.tb00149.x

Serrano, A. (2016). Geografía de la salud. Bloomington, IN: Palibrio.

Smith, N. (1984). Uneven development: Nature, capital and the production of space. Oxford, UK: Blackwell.

Teitz, M. B. (1968). Towards a theory of urban facility location. Papers of the Regional Science Association, 21(1), 35-51. DOI: https://doi.org/10.1111/j.1435-5597.1968.tb01439.x

Townsend, P., e Davidson, N. (1988). The Black Report. En P. Townsend e N. Davidson (Eds.), Inequalities in Health. Suffolk, UK: Penguin.

Urry, J. (1981). Localities, regions and social classes. International Journal of Urban and Regional Research, 5(4), 455-473. DOI: https://doi.org/10.1111/j.1468-2427.1981.tb00563.x

Vasconcellos, E. A. (2000). Transporte urbano nos países em desenvolvimento. São Paulo, Brasil: Annablume.

Vinuesa, J., e Puga, D. (2007). Técnicas y ejercicios de demografía. Madrid: Instituto Nacional de Estadística.

Voogd, H. (1983). Multicriteria evaluation for urban and regional planning. London, UK: Pion. Recuperado de: https://pure.tue.nl/ws/files/3744610/102252.pdf

von Thünen, J. H. (1826). Der Isolierte Staat in Beziehung auf Landtschaft und Nationalökonomie. Hamburg, Germany.

Weber, A. (1909). Úber den Standort der Industrien. Tübingen, Germany: J. C. B. Mohr.

Whitehead, M. (Ed.). (1988). Inequalities in health. Suffolk, UK: Penguin.

Wilkinson, R. G. (1996). Unhealthy socities: The afflictions of inequality. London, UK: Routledge.

Zaidi, S. A. (1994). Planning in the health sector: For whom, by whom? Social Science and Medicine, 39(9), 1385-1393. DOI: https://doi.org/10.1016/0277-9536(94)90369-7 